\title{
A INTERNACIONALIZAÇÃO DE CLARICE LISPECTOR: HISTÓRIA CLARICEANA EM INGLÊS
}

\author{
Cynthia Beatrice Costa* \\ Universidade Metodista de Piracicaba
}

Luana Ferreira de Freitas**

Universidade Federal do Ceará

\begin{abstract}
Resumo: O texto ficcional clariceano vem recebendo a atenção de leitores, estudiosos e editores estrangeiros há cerca de 60 anos, desde a sua chegada à língua francesa, no início dos anos 1950. No presente artigo, pretende-se cobrir, especificamente, a trajetória das traduções de obras de Clarice Lispector para o inglês, idioma para o qual a autora brasileira tem sido com frequência traduzida e na qual experimenta, no momento, o prestígio desencadeado pelo lançamento da antologia The Complete Stories (2015), editada por seu biógrafo Benjamin Moser.
\end{abstract}

Palavras-chave: Clarice Lispector em inglês. Tradução. Recepção.

\footnotetext{
* Possui graduação em Jornalismo pela Faculdade Cásper Líbero (2002) e mestrado em Literatura e Crítica Literária pela Pontifícia Universidade Católica de São Paulo (2008). É doutora pelo Programa de Pós-Graduação em Estudos da Tradução da Universidade Federal de Santa Catarina (2016), com período sanduíche na Universidade de Yale (2015). Atua como professora no curso Letras Inglês - Tradução e Interpretação, da Universidade Metodista de Piracicaba. Piracicaba, São Paulo, Brasil. E-mail: cynthia_costa@uol.com.br

** Graduação em Letra - Tradução (UnB, 1998), mestrado em Linguística Aplicada (UnB, 2003), doutorado em Teoria Literária (UFSC, 2007), pós-doutorado em Estudos da Tradução (UFSC, 2011). Fundadora da Pós-graduação em Estudos da Tradução (POET), atua como professora de Literaturas de língua inglesa na Universidade Federal do Ceará. Fortaleza, Ceará, Brasil. E-mail: luanafreitas. luana@gmail.com
} 


\title{
CLARICE LISPECTOR'S INTERNATIONALIZATION: THE BRAZILIAN AUTHOR'S HISTORY IN ENGLISH
}

\begin{abstract}
Clarice Lispector's fictional work has been given attention by foreign readers, scholars and editors since its first translations into French, which appeared in the beginning of the 1950s. The present article aims to present specifically the history of Lispector's work in the Anglophone literary system - most of her fiction has been translated into the English language, and the recent release of The Complete Stories (2015), edited by her biographer Benjamin Moser, brought even more prestige to the Brazilian author.
\end{abstract}

Keywords: Clarice Lispector in English. Translation. Reception.

Se recebo um presente dado com carinho por pessoa de quem não gosto - como se chama o que sinto? Uma pessoa de quem não se gosta mais e que não gosta mais da gente - como se chama essa mágoa e esse rancor? Estar ocupada, e de repente parar por ter sido tomada por uma desocupação beata, milagrosa, sorridente e idiota - como se chama o que se sentiu? O único modo de chamar é perguntar: como se chama? Até hoje só consegui nomear com a própria pergunta. Qual é o nome? e é este o nome.

Clarice Lispector

Os textos de Clarice, sobretudo sua ficção, causam, de uma maneira geral, reações extremas nos leitores, ou, dito de outra forma, o leitor se identifica e mergulha no jogo ficcional narrativo difuso e nunca circunscrito de Clarice ou o leitor rejeita de imediato o caráter deliberadamente irredutível da escrita da autora, que não se pretende definível, que resiste à depreensão e que não se resolve em si mesma. Assim, pode-se dizer que Clarice é sempre lida com assombro, de uma forma ou de outra.

No embate com o texto clariceano, o leitor, tradutor ou não, enfrenta um contínuo estranhamento: a ruptura da expectativa é constante e o leitor se depara com um uso de língua que não se detém em ser instrumental. A língua é protagonista em Clarice; sua escrita é perturbadora, entre outras coisas, por chamar a atenção 
para si mesma, caracterizando uma de suas principais estratégias estilísticas. Ao mesmo tempo em que essa escrita deixa o leitor ou o tradutor perplexo por perturbar um uso estabelecido de língua, ela rejeita interpretações inequívocas.

Antonio Candido, ao resenhar Perto do coração selvagem, primeiro romance de Clarice, escreveu:

Para que a literatura brasileira se torne grande, é preciso que o pensamento afine a língua e a língua sugira o pensamento por ela afinado. [...] Com relação a Perto do coração selvagem, se deixarmos de lado as possíveis fontes estrangeiras de inspiração, permanece o fato de que, dentro da nossa literatura, é performance da melhor qualidade. A autora, ao que parece uma jovem estreante, colocou seriamente o problema do estilo e da expressão. Sentiu que existe uma certa densidade afetiva e intelectual que não é possível exprimir se não procurarmos quebrar os quadros da rotina e criar imagens novas, novos torneios, associações diferentes das comuns e mais fundamente sentidas. (CANDIDO, 1977, p. XX)

Clarice invoca a rotina em seus escritos e a eleva com epifanias e perplexidades. Dessa forma, uma ação comum, em um dia comum, como ir à feira, contemplar um ovo ou tomar um bonde, torna-se reveladora, epifânica. Para alcançar esse estado, Clarice extrapola limites da língua ao revelar, por vezes, um papel de mulher na sociedade que está em descompasso com o estado de graça alcançado ou revelado.

Benedito Nunes define as personagens clariceanas como "espectadoras dos seus próprios estados e atos, que têm a nostalgia da espontaneidade, enredadas em suas vivências" (1989, p. 105), e acrescenta que elas "obedecem à necessidade de um aprofundamento impossível, e perdem-se entre os múltiplos reflexos de uma interioridade que se desdobra como superfície espelhada e vazia em que se miram" (Ibid.). 
A personagem em Clarice não se resolve, uma vez que deve voltar ao estado anterior das coisas, ao seu estabelecido papel de mulher, em um movimento análogo ao uso de língua na narrativa, que continuamente extrapola e volta ao estado anterior sem se dar à clareza, sem se resolver.

Assim, o desafio do tradutor de Clarice é ter que lidar com o irredutível, com aquilo que não cabe, que não se nomeia, que não se pretende apreensível na língua de partida e manter esse estranhamento, esse assombro na língua de chegada. Soler, tradutora e estudiosa de Clarice para o espanhol, afirma:

\begin{abstract}
A obra de Clarice Lispector é uma constante reflexão sobre a linguagem e, acima de tudo, sobre os limites da palavra. A palavra de Clarice Lispector é rigorosa porque deve traduzir, através de um meio limitado, algo muito maior que a linguagem. Deve traduzir o mistério e o que não tem nome, deve expressar com termos racionais o que está mais além, deve ser capaz de fixar o instante e o ato ínfimo que está na origem do todo. Temos aqui alguns dos motivos recorrentes da sua obra: o olhar, às vezes visionário e impecável, a consagração do instante e a importância do aparentemente banal. ${ }^{1}$ (1994, tradução nossa.)
\end{abstract}

O tradutor de Clarice deve resistir à tentação de simplificar, desmembrar, explicar ou deformar o intrincado estilo narrativo clariceano, seja por iniciativa própria, seja por pressão, ou imposição, do editor. De acordo com Lorenz, tradutor para o inglês de Um sopro de vida, em entrevista concedida a Ozone Park Journal,

\footnotetext{
${ }^{1}$ La obra de Clarice Lispector es una constante reflexión sobre el lenguaje y sobre todo, sobre los límites de la palabra. La palabra de Clarice Lispector es rigurosa porque debe traducir con un medio limitado algo que es mucho más grande que el lenguaje. Debe traducir el misterio y lo que carece de nombre, debe expresar con términos racionales lo que la mirada percibió más allá, debe ser capaz de fijar el instante y el acto ínfimo que está en el origen de todo. Tenemos ya aquí algunos de los motivos recurrentes de su obra: la mirada, a la vez visionaria e implacable, la consagración del instante y la importancia de lo aparentemente banal.
} 
“o tradutor trabalha com os silêncios de um texto. Às vezes, somos tentados a dizer demais numa tradução, num esforço de impor nossa própria interpretação de um fragmento" ${ }^{2}$ (2014). E, mais adiante, comenta:

Ela [Clarice] está constantemente questionando palavras, pressionando-as, despindo-as, exaurindo-as. Há um equilíbrio difícil aqui, para o tradutor, porque eu não queria que essas frases soassem como uma tradução desastrada! Mas eu queria que as frases em inglês fossem tão estranhas e maravilhosas como são em português ${ }^{3}$. (2014, tradução nossa.)

É sabido que a própria Clarice, ela mesma tradutora, teve uma má reação diante da primeira tradução de um romance seu para uma língua estrangeira - em 1954, a editora parisiense Plon publicou Près du coeur sauvage, tradução de Perto do coração selvagem assinada por Denise-Teresa Moutonnier e supervisionada pelo editor Pierre de Lescure. A autora brasileira, em carta para Lescure, acusou a tradução de ser "escandalosamente ruim", mas se retrataria mais tarde por esse seu "mau comportamento" (MOSER, 2009, p. 187). De toda forma, ela sempre pareceu pouco receptiva a traduções feitas a partir de textos seus: "Traduzo, sim, mas fico cheia de medo de ler traduções que fazem de livros meus. Além de ter bastante enjoo de reler coisas minhas, fico também com medo do que o tradutor possa ter feito com um texto meu" (LISPECTOR, 2005, p. 117).

Apesar da complexidade do texto clariceano, novas iniciativas tradutórias de fôlego em língua estrangeira estão sendo tomadas

\footnotetext{
${ }^{2}$ The translator works with the silences of a text. Sometimes we are tempted to say too much in a translation, in an effort to push our own interpretation of a passage.

${ }^{3}$ She is constantly interrogating words, pressing them, stripping them down, exhausting them. There is a difficult balancing act here for the translator, because I didn't want these sentences to read like a clumsy translation! But I wanted the sentences in English to be as weird and as wonderful as they are in Portuguese.
} 
nos últimos anos. Citamos três recentes exemplos emblemáticos de iniciativas de divulgação da obra de Clarice no estrangeiro: a compra dos direitos de publicação da obra de Clarice Lispector pela editora alemã Schöffling \& Co., a publicação da antologia The Complete Stories ${ }^{4}$ de Benjamin Moser, com a reunião de todos os contos de Clarice para o inglês, a ser abordada mais adiante, e a coleção Biblioteca Clarice Lispector ${ }^{5}$ da editora espanhola Siruela, a mesma editora da famosa coleção Biblioteca de Babel, dirigida por Jorge Luis Borges.

De acordo com a editora, a coleção dedicada a Clarice tem o objetivo de "reunir a obra de uma das escritoras fundamentais da literatura contemporânea: a brasileira Clarice Lispector6 ." (201?. Tradução nossa). A coleção conta atualmente com nove títulos: La pasión según G. H., Cuentos reunidos, Agua viva, La hora dela estrella, La manzana en la escuridad, Aprendizaje o el libro de los placeres, Cerca del corazón salvaje, Un soplo de vida e Donde se enseñerá a ser feliz. Além dos títulos que compõem a citada coleção, a editora disponibiliza outros títulos da autora na coleção Libros del Tiempo: Queridas mías, correspondência; Correo feminino, crônicas; Aprediendo a vivir, crônicas; Para non olvidar, crônicas; Sólo para mujeres, crônicas; La ciudad sitiada e La lámpara.

Como acontece com textos complexos, Clarice continua sendo traduzida, retraduzida e reeditada, indicando não apenas a curiosidade que seus escritos despertam como também a necessidade de revisitá-los. Vale ressaltar ainda que de acordo com a Fundação Biblioteca Nacional, os dados do Programa de Apoio à Tradução e à Publicação de Autores Brasileiros no Exterior mostram que

\footnotetext{
${ }^{4}$ Essa tradução foi viabilizada pelo Programa de Apoio à Tradução e à Publicação de Autores Brasileiros no Exterior, promovido pela Biblioteca Nacional.

${ }^{5}$ Ver http://www.siruela.com/catalogo.php?opcion=buscar\&id_autor $=207$

${ }^{6}$ Reunir la obra de una de las escritoras fundamentales de la literatura contemporá: la brasileña Clarice Lispector.
} 
Clarice Lispector desponta como autora mais solicitada por editoras estrangeiras, acompanhada de perto por Machado de Assis. Chega a 40 o número de apoios concedidos a projetos de tradução de seus livros, para 16 idiomas em 20 países diferentes. Entre os títulos, A hora da estrela é o mais requisitado, seguido de Um sopro de vida, a Paixão segundo G.H. e Perto do coração selvagem. (2016, [s.p.].)

Nosso objetivo aqui é tentar traçar a história de Clarice Lispector no sistema literário anglófono, sobre o que nos deteremos a seguir.

\section{Breve histórico de Clarice Lispector em inglês}

Clarice teve sua estreia em língua inglesa em 1960, com The Apple in the Dark, tradução de A maçã no escuro (1961) assinada por Gregory Rabassa (1922-2016), que traduziu também, entre outros autores latino-americanos, Machado de Assis e Gabriel García Márquez. A tradução de Rabassa teve seis reimpressões, sendo a última em 2009.

No verão de 1964, a poeta norte-americana Elizabeth Bishop, que costuma ser considerada uma espécie de arauto do talento de Clarice Lispector em língua inglesa, publica as suas traduções de três contos de Clarice na revista The Kenyon Review, editada pela faculdade Kenyon College, localizada no estado de Ohio. "The Hen" é a tradução de "Uma Galinha", "The Smallest Woman in the World", de "A menor mulher do mundo" e "Marmosets", por sua vez, é a tradução para "Macacos". A revista apresentou o trio de traduções como "Três Contos de Clarice Lispector - Traduzidos do Português por Elizabeth Bishop" ("Three Stories by Clarice Lispector - Translated from Portuguese by Elizabeth Bishop").

A partir da década de 1970, o estudioso escocês Giovanni Pontiero (1932-1996) dá início à sua empreitada de traduções clariceanas. Conhecido, sobretudo, por ser tradutor de José Saramago 
para a língua inglesa ${ }^{7}$, Pontiero dava aulas de literatura latino-americana na Universidade de Manchester, na Inglaterra. Em 1972, publica Family Ties, tradução da coletânea de contos Laços de família (1960), pela coleção Texas Pan American Series, da University of Texas Press. A antologia teve outras cinco edições, sendo a última em 2012.

A partir dos anos 1980, as traduções para o inglês da ficção longa de Clarice Lispector se multiplicaram. Em 1982, o norte-americano Earl E. Fitz, estudioso de literatura brasileira, traduz o livro infantil $A$ Mulher que matou os peixes (1969) para a revista Latin American Review como The Woman Who Killed the Fish ${ }^{8}$. Fitz voltaria a traduzir Clarice outras vezes ao longo dos anos.

Ainda no ano de 1985, o conto "A imitação da rosa" aparece como "The Imitation of the Rose" na coletânea Other Fires: Short Fiction by Latin-American Women, traduzido e organizado por Alberto Manguel para a editora Three Rivers Press, com prefácio de Isabel Allende.

Em 1986, Pontiero publica pela britânica Carcanet Press The Foreign Legion: Stories and Chronicles, da coletânea de contos Legião estrangeira (1964), que conta ainda com outra edição, e The Hour of the Star, sua tradução de $A$ hora da estrela, que teve outras quatro reimpressões, duas em 1987, uma em 1989 e uma em 1992. Em 2011, Benjamin Moser apresenta a sua retradução do romance já lançado em uma segunda edição.

Ainda no ano de 1986, a dupla de tradutores Richard A. Mazzara e Lori A. Parris retomam Clarice na coleção Texas Pan American Series, da University of Texas Press, com An Apprenticeship or The Book of Delights, tradução de Uma Aprendizagem ou $O$

\footnotetext{
${ }^{7}$ Pontiero também traduziu obras das brasileiras Lygia Bojunga Nunes, Ana Miranda e Lya Luft, entre outros autores de língua portuguesa.

${ }^{8}$ Existem dúvidas a respeito da origem da tradução de outro conto infantil, "O mistério do coelho pensante". A tradução datilografada "The Mystery of the Thinking Rabbit" (1975) consta no acervo da Fundação Casa de Rui Barbosa e foi, supostamente, realizada pela professora californiana Suzanne Jill Levine com ajuda da própria Clarice (STUERMER e NOLASCO, 2011).
} 
livro dos prazeres (1969). Parris tinha traduzido o texto para a sua tese de doutorado, em 1982. Trata-se da única versão em inglês desse romance até o momento.

Em 1988, Ronald W. Sousa é responsável pela tradução The Passion According to G.H. para a University of Minnesota Press, retraduzido por Idra Novey e com uma introdução assinada por Caetano Veloso, pela editora New Directions, em 2012, reeditado em 2014.

Em 1989, os norte-americanos Elizabeth Lowe e Earl Fitz, ambos estudiosos de literatura brasileira, traduzem Água viva como The Stream of Life para a coleção Exxon Lecture Series, da mesma editora. O romance foi retraduzido com o título em português, em 2012, por Stefan Tobler - este também tradutor de Raduan Nassar. A crítica literária feminista francesa Hélène Cixous, de origem judaica e nascida na Argélia, responsável pelo prefácio de The Stream of Life, publicaria, ainda pela University of Minnesota Press, o ensaio "Reading with Clarice Lispector" em 1990, consolidando o interesse dessa editora acadêmica pela autora brasileira - apresentada na capa do livro de Cixous, traduzido do francês para o inglês por Verena Andermatt Conley, como "a principal prosadora latino-americana deste século" ("the premiere Latin-American woman prose writer of this century").

Em 1989, a New Directions, editora nova-iorquina que vem seguindo com o projeto de propagar Clarice em língua inglesa até a atualidade, lança Soulstorm: Stories by Clarice Lispector, tradução de Alexis Levitin de $A$ via crucis do corpo com introdução de Grace Paley.

Em 1990, é lançada tardiamente - 35 anos depois de sua primeira publicação em francês - a tradução de Giovanni Pontiero de Perto do coração selvagem (1943), primeiro romance de Clarice, como Near to the Wild Heart - A Novel by Clarice Lispector ${ }^{9}$, pela editora New Directions. Em 2012, a tradutora australiana Alison

${ }^{9}$ Para uma crítica dessa tradução, ver "Perto do coração selvagem em inglês", de Luana Ferreira de Freitas, Revista Cerrados, n. 24, p. 279-286, 2007.

Cad. Trad., Florianópolis, v. 37, n⿳2 2, p. 40-54, mai-ago 2017 
Entrekin, responsável por verter para o inglês obras de variados autores brasileiros contemporâneos, como Daniel Galera e Chico Buarque, lança Near to the Wild Heart, sua retradução de Perto do coração selvagem, reeditado em 2014.

No início dos anos 1990, Clarice integra, ainda, duas antologias. Em Short Stories by Latin American Women, com edição de Cecilia Correas Zapata e introdução de Isabel Allende, o conto escolhido foi "Looking for Some Dignity", tradução de Leland Guyer de "À procura de uma dignidade", integrante de A legião estrangeira. Para A Hammock Beneath the Mangoes: Stories from Latin America, o editor Thomas Colchie escolheu o conto "Amor", traduzido por ele como "Love".

Em 1992, Pontiero volta à Carcanet Press com Discovering the World, tradução de $A$ descoberta do mundo. Trata-se da coletânea de textos publicados pela escritora no Caderno $B$ do Jornal do Brasil entre 1967 e 1973, organizada postumamente, em 1984, por seu filho, Paulo Gurgel Valente.

Após a morte do tradutor, a Carcanet Press publica, ainda, The Besieged City, tradução de Pontiero do romance $A$ cidade sitiada. Há uma edição de 1997 e outra de 1999 dessa tradução. Pouco antes, em 1996, a editora New Directions compôs o volume Selected Cronicas: Essays, que reúne 157 das 468 crônicas de $A$ descoberta do mundo traduzidas por Pontiero.

Em 1998, Clarice apareceria em The Oxford Book of Jewish Stories, com o conto Family Ties, outra tradução de Pontiero, publicada no livro homônimo de 1972. A antologia foi organizada por Ilan Stavans.

Estudioso da literatura brasileira nos Estados Unidos, K. David Jackson também destacaria Clarice em uma nova antologia, em 2006: a Oxford Anthology of the Brazilian Short Story, na qual se encontram nove traduções de contos clariceanos, todos publicados em Family Ties, tradução de Pontiero de 1972.

Em 2009, Benjamin Moser lança a biografia de Clarice em português (Clarice, pela editora Cosac Naify, e Clarice Lispector, uma vida, pela Editora Civilização, traduzida por José Geraldo 
Couto) e em inglês (Why this World: a Biography of Clarice Lispector, pela Oxford University Press).

2012, Idra Novey, estudiosa de Clarice e segunda tradutora de Paixão segundo G.H., traduz Um sopro de vida, A Breath of Life, publicada com prefácio, na verdade uma troca de correspondência, entre Benjamin Moser e Pedro Almodóvar discutindo o romance. A tradução foi reeditada em 2014.

Em agosto de 2015, é lançado nos Estados Unidos The Complete Stories, organizado por Benjamin Moser e traduzido por Katrina Dodson. Essa antologia foi recebida com entusiasmo pela impren$\mathrm{sa}^{10}$ norte-americana, mas não é unanimidade entre estudiosos.

Nadia Batella Gotlib, professora de literatura brasileira na Universidade de São Paulo e especialista reconhecida em Clarice, que já publicou artigos e biografias sobre a escritora, não se mostrou muito favorável à antologia de Moser. Gotlib destaca a incoerência dos critérios adotados para a seleção dos textos. A especialista chama a atenção para o fato de Moser ter incluído, além de contos, textos de outra natureza, como peça de teatro, textos jornalísticos e crônicas. Apesar de aludir à natureza fugidia de gênero na produção clariceana, Gotlib censura a falta de rigor na organização dos textos levando em consideração a promessa no título: The Complete Stories. Apesar da crítica, Gotlib reconhece que a noção de gêneros em Clarice é complexa e defende Woodward, antologista dos contos de Clarice para o espanhol, que usou como critério para seleção de contos o que a própria Clarice considerou conto. Gotlib diz: "Portanto, se o que se propõe neste volume de "todos os contos" é mesmo a "totalidade" dos contos, melhor seria separar logo no índice o que é do que não é conto" (2016, [s.p.]).

Gotlib parece ter razão em sua crítica quanto à elasticidade de critérios em uma antologia que se pretende de contos, mas a empreitada de Moser não deixa de ser louvável. Ele não apenas

\footnotetext{
${ }^{10}$ Ver, por exemplo, < http://www.nytimes.com/2015/08/02/books/review/the-completestories-by-clarice-lispector.html >, <http://www.nybooks.com/articles/2015/12/17/clarice-lispector-played-hard-happiness/ $>$ e $<$ http://harvardreview.fas.harvard.edu/?q= features/book-review/complete-stories $>$.
}

Cad. Trad., Florianópolis, v. 37, n⿳2 2, p. 40-54, mai-ago 2017 
deu visibilidade à escritora com sua antologia no sistema literário anglófono, mas chacoalhou igualmente a crítica clariceana. Tanto é verdade que a antologia de Moser foi publicada pela Roxo no corrente ano, faltando, em sua versão brasileira, apenas as notas da tradutora e os agradecimentos. Não há dúvida de que título e miolo de The Complete Stories estão em desalinho, mas Moser foi pioneiro ao reuniu em um só volume a contística de Clarice, o que nunca tinha sido feito em lugar nenhum, nem mesmo no Brasil.

A narrativa ficcional de Clarice está bem representada em inglês: das duas antologias de crônicas organizadas no Brasil, uma, $A$ descoberta do mundo, foi traduzida. Dos seus nove romances, apenas $O$ lustre não foi traduzido; dos oito traduzidos apenas um não foi reeditado, Uma aprendizagem ou o livro dos prazeres. A hora da estrela, Paixão segundo G.H., Água viva e Perto do coração selvagem contaram, cada um, com uma retradução. Dos livros para o público infantil, apenas $A$ mulher que matou os peixes foi, de fato, publicado em inglês. No tocante aos contos, além de as coletâneas Laços de família, Legião estrangeira e $A$ via crucis do corpo terem sido traduzidas, a recente empreitada de Moser em The Complete Stories e o sucesso alcançado por essa antologia parecem apontar para a solidez do lugar de Clarice naquele sistema literário.

\section{Referências}

ARÊAS, V. Clarice Lispector com a ponta dos dedos. São Paulo: Companhia das Letras, 2005.

CANDIDO, A. "No raiar de Clarice Lispector". In: CANDIDO, A. Vários escritos. São Paulo: Duas Cidades, 1977. 
EDICIONES SIRUELA. Biblioteca Clarice Lispector. Disponível em: $<$ http:// www.siruela.com/catalogo.php?opcion $=$ buscar\&id_autor $=207>$. Acesso em: 3 set. 2016.

EDWARDS, Magdalena. The Translator's Colors: Elizabeth Bishop in Brazil and Elsewhere. Tese de doutorado. 2007. 284 f. Tese (Doutorado) - University of California, Los Angeles, 2007.

FUNDAÇÃO BIBLIOTECA NACIONAL. "Tradução de Clarice Lispector para o inglês conquista reconhecimento". Disponível em: < https://www.bn.br/ acontece/ noticias/2016/04/traducao-clarice-lispector-ingles-conquista $>$. Acesso em: 11 set. 2016.

GOTLIB, N. B. "De Cuentos reunidos a Todos os contos". Cult. Disponível em: $<$ http://revistacult.uol.com.br/home/2016/07/de-cuentos-reunidos-a-todos-oscontos/ > . Acesso em: 2 set. 2016.

JACKSON, K. D. (Ed.). Oxford Anthology of the Brazilian Short Story. Nova York: Oxford University Press, 2006.

LEONARD, K. S. Latin American Women Writers: a Resource Guide to Titles in English. Lanham; Toronto; Plymouth: The Scarecrow Press, 2007.

LISPECTOR, C. The Apple in the Dark. Trad. Gregory Rabassa. Londres: Paul Hamlyn, 1960.

. The Apple in the Dark. Trad. Gregory Rabassa. Londres: Haus Publishing, 2009.

. A Breath of Life. Trad. Idra Novey. Nova York: Penguin Books, 2014.

. The Complete Stories. Trad. Katrina Dodson. Nova York: Penguin

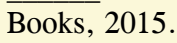

. The Complete Stories. Trad. Katrina Dodson. Nova York: New Directions, 2015. 
. The Crime of the Mathematics Professor. Trad. Giovanni Pontiero. In: ECHEVARRÍA, Roberto G. (Ed.). The Oxford Book of Latin-American Short Stories. Nova York: Oxford University Press, 1997.

. Family Ties. Trad. Giovanni Pontiero. Austin: The University of Texas Press, 1973.

. Family Ties. In: STAVANS, Ilan (Ed.). The Oxford Book of Jewish

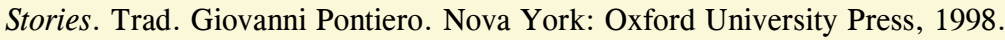
1992.

. Foreign Legion. Trad. Giovanni Pontiero. Nova York: New Directions,

. A Hen. Trad. Elizabeth Bishop. In: The Kenyon Review, v. 26, n. 3, p. $\overline{500-506,} 1964$.

. The Hour of the Star. Trad. Benjamin Moser. Nova York: Penguin Books, 2014.

. The Imitation of the Rose. Trad. Alberto Manguel. In: MANGUEL, Alberto. Other Fires: Short Fiction by Latin-American Women. Londres: Picador Books, 1986.

. Looking for Some Dignity. Trad. Leland Guyer. In: ZAPATA, Cecilia Correas (Ed.). Short Stories by Latin American Women: the magic and the real. Houston: Arte Publico Press, 1990.

. Marmosets. Trad. Elizabeth Bishop. In: The Kenyon Review, v. 26, n. 3, p. 509-511, 1964. Books, 2014.

. The Passion According to G.H. Trad. Idra Novey. Nova York: Penguin . The Smallest Woman in the World. Trad. Elizabeth Bishop. In: The Kenyon Review, v. 26, n. 3, p. 507-509,1964. 
. The Smallest Woman in the World; Marmosets. Trad. Elizabeth Bishop. In: HOWES, Barbara (Ed.). The Eye of the Heart: Short Stories from Latin America. Indianapolis: Bobbs-Merrill, 1973.

LORENZ, J. Translating Clarice Lispector: A Conversation with Johnny Lorenz. Disponível em: <http://ozoneparkjournal.com/interviews/translating-claricelispector-a-conversation-with-johnny-lorenz/ > . Acesso em: 4 set. 2016.

MARSAK, R. The Translator's Dialogue. In: ORERO, Pilar; SAGER, Juan C. The Translator's Dialogue: Giovanni Pontiero. Filadélfia: John Benjamins Publishing Co, 1997.

MIROIR, J-C. Clarice Lispector e seus tradutores: da fúria à melodia. In: O eixo e a roda, Belo Horizonte, v. 25, n. 1, p. 61-85, 2016.

MOSER, B. Clarice. São Paulo: Cosac Naify, 2009.

NUNES, B. O drama da linguagem: uma leitura de Clarice Lispector. São Paulo: Ática, 1989.

SOLER, L. E. Clarice Lispector: la palavra rigurosa. Disponível em: < https:// pendientedemigracion.ucm.es/info/especulo/numero4/lispecto.htm $>$. Acesso em: 4 set. 2016.

STUERMER, L; NOLASCO, E. "O mistério da tradução em Clarice Lispector: uma análise comparatista entre $O$ mistério do coelho pensante e The Mystery of The Thinking Rabbit". In: Congresso Nacional de Estudos Linguísticos e Literários (EPGL), VII, Universidade Federal do Mato Grosso do Sul, Campo Grande, MS, 2011.

Recebido em: 17/10/2016

Aceito em: 28/12/2016

Publicado em maio de 2017 